\title{
The way forward with dental student communication at the University of the Western Cape, Cape Town, South Africa
}

\author{
R Maart, ${ }^{1}$ BChD, MPhil (Higher Education); K Mostert-Wentzel, ${ }^{2}$ MPhysT, MBA, PhD
}

${ }^{1}$ Department of Prosthetics, Faculty of Dentistry, University of the Western Cape, Cape Town, South Africa

${ }^{2}$ Department of Physiotherapy, Faculty of Health Sciences, University of Pretoria, South Africa

Corresponding author: R Maart (rmaart@uwc.ac.za)

Background. Dental students are extensively trained to provide dental treatment to their patients during the undergraduate programme. However, no or little time is spent on the training of basic communication skills. Embedding a communication course in the curriculum would require support of the teaching staff and clinical teachers.

Objective. To explore the perceptions of the clinical teachers with regard to the teaching and learning of dental student communication.

Methods. The study had a two-phase, sequential, exploratory, mixed-methods research design. The first phase explored the lecturers' perceptions of dental student-patient communication by means of a focus group interview $(n=5)$. Findings were used to develop the questionnaire for the second phase. The survey was distributed to 57 clinical teachers using the online SurveyMonkey system (USA).

Results. Sixty-three percent rated dental student-patient communication as good. All the respondents thought communication skills should be included in the dental curriculum. Of the total, $47 \%$ strongly agreed that students wish to continue with their work and not attend to communication. Of the clinical teachers, $47 \%$ strongly agreed that they need training on how to communicate and assess communication skills. Sixty-eight percent strongly agreed that developing and teaching a communication module should be shared among faculty staff.

Conclusion. Clinical teachers agreed that communication skills training and clinical assessment in the dental curriculum are important. The study raised awareness among faculty members about the importance of communication skills and ensured initial buy-in for the development of such a course.

Afr J Health Professions Educ 2016;8(1):69-71. DOI:10.7196/AJHPE.2016.v8i1.571

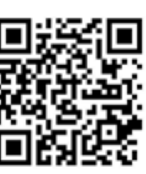

Clinical, scientific and interpersonal skills have been recognised as important components of the dental curriculum. Good interpersonal skills enhance studentto-patient relationships. ${ }^{[1,2]}$ Communication is one of the salient skills in clinicians' relationship with patients. It is an element that is often overlooked and underemphasised, both at dental school and in continuing education. ${ }^{[3]}$ Dental students at the University of the Western Cape (UWC), Cape Town, South Africa (SA) are thoroughly trained to provide dental treatment to their patients during their undergraduate programme; however, little time is spent on teaching and learning basic communication skills. At this institution the emphasis is directed towards ensuring that students are competent clinicians. However, the literature shows that the ability to communicate effectively with patients is crucial; the better communicators we are, the better clinicians we will become. ${ }^{[2,3]} \mathrm{A}$ communication course for dental students at UWC would be necessary to improve dental student communication.

The inclusion of a communication course has human resource implications; the course has to be designed, taught, assessed and evaluated. The success of curricular change requires faculty buy-in and consensus. ${ }^{[3]}$ Being confronted with a paradigm shift in dental education can create uncertainty and resistance among faculty. ${ }^{[4]}$ Embedding a communication course in the undergraduate dental curriculum at the UWC dental school would require the support of all teaching staff and clinical teachers. Therefore, the purpose of this research was twofold: (i) to explore perceptions; and (ii) to create awareness among clinical teachers with regard to dental student communication.

\section{Methods}

Ethical clearance for the research was obtained from the Dental Faculty Ethics Committee, UWC (reference 13/4/36). Written consent was obtained from all participants.

A sequential mixed-methods research design was chosen. This research was conducted at the UWC dental faculty in 2013. First, qualitative data were collected from a focus group discussion with dental clinical teachers $(n=5)$. During this discussion, the clinical teachers were asked to give their opinions on how students communicate and empathise with patients; if and how a communication skills course should be included in the undergraduate curriculum; possible education strategies to improve dental communication between students and patients; and involvement of faculty in future communication education. Data from the interview guided the development of the questionnaire used in the second phase of the survey. Quantitative data were collected from this phase of the survey.

SurveyMonkey, an online cloud-based survey tool (USA), was used to distribute the survey to all full- and part-time clinical teachers $(n=57)$. Closedand open-ended questions were used in the survey. Data were entered on a Microsoft Office Excel 2010 spreadsheet, descriptive data analysis was applied to the closed-ended questions, and common themes were identified.

\section{Results}

Thirty-five percent of clinical teachers $(n=20)$ completed the questionnaire. Thirty-seven percent of the respondents had $11-15$ years of clinical teaching experience, $58 \%$ were female and $79 \%$ were full-time employees at UWC. Forty-two percent were between the ages of 31 and 40 years, $26 \%$ between 51 and 60 years, and only $11 \%<30$ years. 
Sixty-three percent rated dental student communication with patients as good, although $47 \%$ strongly agreed that students just want to 'get on with the work' and that they see patients as quotas; a definite lack of empathy with patients was observed.

Although only $53 \%$ strongly agreed that communication skills can be taught, 63\% often commented on the student-to-patient communication during clinical supervision of students. Forty-seven percent strongly agreed that communication skills with patients should form part of the education of the clinical assessment. All of the respondents indicated that communication skills should be included in the dental curriculum in future. Sixty-four percent suggested that communication skills should be taught during the 2nd and 3rd years, while $26 \%$ suggested that these skills should be taught throughout the 5-year dental curriculum (Fig. 1). The majority of respondents (84\%) agreed that video-recording of student-topatient communication and case discussions should be included as teaching methods in the communication skills course. The recommended education strategies are shown in Fig. 2.

Forty-seven percent of clinical teachers agreed that they need training on how to communicate and assess communication skills effectively.

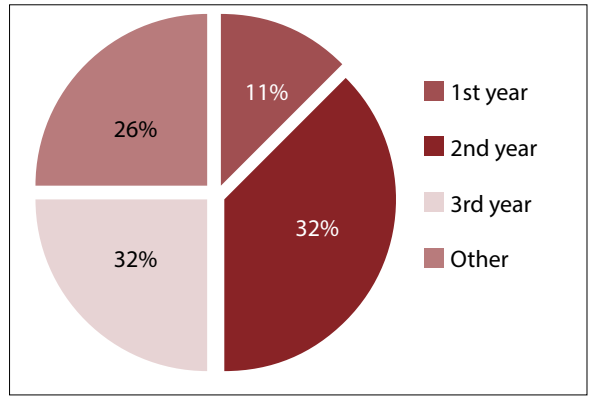

Fig. 1. Participants' response with regard to where in the curriculum communication skills should be taught.

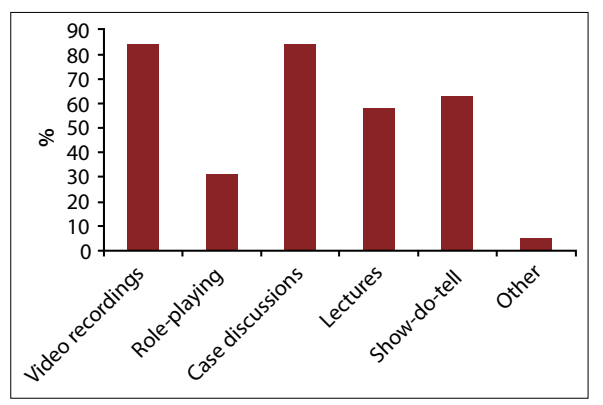

Fig. 2. Participants' response (\%) with regard to which teaching methods should be included in the teaching of communication skills.
Furthermore, 68\% strongly agreed that developing and teaching a communication module should be shared among faculty members and not become the responsibility of one department only.

The findings need to be interpreted with caution, in light of the limited participation of departments in the focus group discussion and the low response rate for the questionnaire.

\section{Discussion}

The objective of this study was to explore the perceptions of clinical teachers with regard to dental student communication and its teaching and learning. The sample included clinical teachers with regard to years of experience, clinical field of interest, gender, and age, and working mostly full time. From the findings of the survey it is clear that the clinical teachers agree that dental student-to-patient communication is important.

Although the majority were of the opinion that students already demonstrate good communication skills, a lack of empathy with patients was observed. The ability to convey messages clearly to patients, listen, be observant and respond to patients' needs, empathise, understand and carry out consultations in an organised and a professional manner are considered basic requirements of a competent dentist. ${ }^{[1]}$

The clinical teachers agreed that a communication skills module should be included in the future dental curriculum. They suggested that such a course be embedded throughout the curriculum; the objective of this strategy would be to align what is taught and assessed. The inclusion of communication-related topics in a dental curriculum was also favoured in a study by Woelber et al ${ }^{[5]}$ and Cannick et al. ${ }^{[6]}$ The integration ladder in curriculum planning has been accepted as an important educational strategy in medical education and can be used as an aid to planning, implementing and evaluating the medical curriculum. ${ }^{[7]}$ The higher one is on the integration ladder, the more important communication and joint planning between teachers become, requiring greater participation by staff. ${ }^{[7]}$

The results have suggested video-recordings and case discussions as educational strategies to teach communication in the dental curriculum. Educational strategies tend to vary in type and duration between studies, but those used appear to be similar, involving a mixture of didactic episodes and clinical scenarios. ${ }^{[8]}$ If the purpose of education is to provide students with appropriate skills, the lecture-only approach in many dental schools is not sufficient. Active practice is necessary to learn communication skills. ${ }^{[9]}$ Role-playing was highlighted as a possible teaching strategy, which corresponds to findings from Woelber et al..$^{[5]}$ and Rider and Keefer. ${ }^{[10]}$ The latter suggest rolemodelling as a teaching strategy to be explored formally in the communication skills of modules and informally by all clinical teachers. The use of simulated patients who are skilled at presenting complex clinical conditions, monitoring students' performance, and delivering specific feedback are components of a communication skills course. ${ }^{[1]}$ Clinically relevant scenarios enable students to develop skills such as problem-solving, increased knowledge of referral processes, and awareness of ethical/legal issues. ${ }^{[1]}$ Evidence from studies that used video-reviewing for learning and assessment supported its use, and it was well received by the majority of students. Only the student and patient need to be present for the consultation, which might minimise the feeling of 'unreality' of scenarios when one is simultaneously observed by peers, as reported by some students..$^{[8]}$

In addition to including such a course, clinical teachers have nevertheless admitted that they require training in teaching and assessing communication skills. Faculty development can be a powerful tool in initiating and setting the direction for curricular change. ${ }^{[3]}$ Bylund et al. ${ }^{[12]}$ showed that teaching and encouraging facilitators can lead to positive outcomes when training students in communication skills.

A foundation for future staff participation during curriculum development and integration was established by engaging clinical teachers during the focus group interviews and participating in the questionnaire. Faculty buyin and participation in curricular change are essential in any academic context and therefore need to be prioritised. Curriculum planners often initiate and plan curriculum changes without consultation with the faculty members responsible for the implementation. This topdown approach is frequently met by faculty resistance; therefore, we recommended that faculty buy-in and participation in curriculum change are considered as viable alternative strategies.

Embedding communication into the undergraduate curriculum has an effect on human resources. Faculty members developing the course need to include teaching and assessment of this aspect, as a new course adds to the work load. Human resource planning needs to form part of the curriculum planning process to ensure that the desired educational outcome is achieved. 


\section{Conclusion}

From the results of this study it is apparent that the clinical teachers agree that effective communication skills are important in dental student training and should be included in the curriculum. The study demonstrated a way of raising awareness in the faculty about the importance of communication skills and ensured initial buy-in for the development and integration of such a communication course. After this study, embedding communication throughout the dental undergraduate curriculum, and implementation and evaluation thereof, are recommended.

Acknowledgements. The authors thank Mrs Y Erasmus for her assistance with the data collection. We also acknowledge the sub-Saharan African Foundation for Advancement of International Medical Education and Research (FAIMER) Regional Institute (SAFRI) for its support.

\section{References}

1. Gonzalez M, Abu Kasim N, Naimie Z. Soft skills and dental education. Eur J Dent Educ 2013;17(2):73-82. [http:// dx.doi.org.10.1111/eje.12017]

2. Abu Kasim NH, Abu Kassim NL, Razak AA, et al. Pairing as an instructional strategy to promote soft skill amongst clinical dental students. Eur J Dent Educ 2014;18(1):51-57. [http://dx.doi.org/10.1111/eje.12058]

3. Steinert Y, Cruess S, Cruess R, et al. Faculty development for teaching and evaluating professionalism: From programme design to curriculum change. Med Educ 2005;39:27-136.

4. Spallek H, O'Donnell J, Yoo Y. Preparing faculty members for significant curricular revisions in a school of denta medicine. J Dent Educ 2010;74(3):75-288.

5. Woelber J, Deimling D, Langenbach D, et al. The importance of teaching communication in dental education: $A$ survey amongst dentists, students and patients. Eur J Dent Educ 2012;16(1):e200-e204.

6. Cannick F, Horowitz A, Garr D, et al. Use of the OSCE to evaluate brief communication skills training for dental students. J Dent Educ 2007;71(9):1203-1209.

7. Harden R. The integration ladder: A tool for curriculum planning and evaluation. Med Educ 2000;34:551-557.

8. Carey J. Madill A, Manogue M. Communications skills in dental education: A systemic research review. Eur Dent Educ 2010;14:69-78. [http://dx.doi.org.10.1111/j.1600-0579.2009.00586.x]

9. Yoshida T, Milgrom P, Coldwell S. How do US and Canadian dental schools teach interpersonal communication skills? J Dent Educ 2002;66(11):1281-1288.

0. Rider E, Keefer C. Communication skills competences: Definitions and a teaching toolbox. Med Educ 2006;40:624-629. [http://dx.doi.org/10.1111/j.1365-2929.2006.02500.x]

1. Hannah A, Millicahamp J, Ayers K. A communication course for undergraduate dental students. J Dent Educ 2004;68(9):970-977.

12. Bylund C, Brown R, Lubrano di Ciccone B, et al. Training faculty to facilitate communication skills training: Development and evaluation of a workshop. Patient Educ Couns 2008;70:430-436. [http://dx.doi.org.10.1016/j.pec.2007.11.024] 